International Journal of Environment, Agriculture and Biotechnology
Vol-6, Issue-2; Mar-Apr, 2021
Journal Home Page Available: $\underline{\text { https://ijeab.com/ }}$
Journal DOI: $10.22161 /$ ijeab

\title{
Engineering Bacillus Subtilis for the production of High Fructose Syrup: Opportunities and Prospects
}

\author{
Ildephonse Habimana ${ }^{1}$, Qiao Zhina ${ }^{1}$, Aqeel Sahibzada Muhammad ${ }^{2}$, Jean Damascene \\ Harindintwali ${ }^{1}$, Abdulqader Al-Adeeb ${ }^{1}$, Waleed AL-Ansi ${ }^{3,4}$, Tolbert Osire ${ }^{a}$, Mengkai \\ $\mathrm{Hu}^{1}$, Meijuan $\mathrm{Xu}^{1}$, Xian Zhang ${ }^{1}$, Zhiming Rao ${ }^{1, *}$
}

\author{
${ }^{1}$ The Key Laboratory of Industrial Biotechnology, Ministry of Education, School of Biotechnology, Jiangnan University, 1800 Lihu \\ Avenue, Wuxi 214122, Jiangsu, China \\ ${ }^{2}$ National Engineering Laboratory for Cereal Fermentation Technology, Ministry of Education, School of Biotechnology, Jiangnan \\ University, 1800 Lihu Avenue, Wuxi 214122, Jiangsu, China \\ ${ }^{3}$ School of Food Science and Technology, State Key Laboratory of Food Science and Technology, Jiangnan University, 1800 Lihu \\ Avenue, Wuxi 214122, China. \\ ${ }^{4}$ Department of Food Science and Technology, Faculty of Agriculture, Sana'a University, Sana'a, Yemen. \\ *Corresponding Author
}

Received: 20 Dec 2020; Received in revised form: 22 Feb 2021; Accepted: 20 Mar 2021; Available online: 13 Apr 2021 (C)2021 The Author(s). Published by Infogain Publication. This is an open access article under the CC BY license (https://creativecommons.org/licenses/by/4.0/).

\begin{abstract}
High fructose syrup is an excellent and safe sweetener that can replace sucrose and is widely used in beverages and food products, including soft drinks, ketchup, yogurt, ice cream, chocolate milk, candies, jams, condiments, canned and packaged foods, etc. Besides, after acid dehydration, it can be used as a renewable resource to synthesize bio-petrochemicals. The advantages of high fructose syrup include high sweetness, high solubility, low viscosity, enhanced flavor, good moisture retention, no side effects in acidic foods, and no crystal formation. Due to its potential application, little has been done to satisfy the current market. It can be produced by two main approaches, (i)Chemical method of synthesis accounted several challenges and these include low yield, unacceptable products, expensive, environmentally unfriendly. This review aimed to discuss the engineering B. subtilis 168 which a food-grade microbial cell factory to solve all the challenges from chemical production processes with an improved yield, cost-effective, environmentally friendly, and quality products.GI which isomerizes a reversible reaction of D-glucose into D-fructose requires special conditions for the highlevel yield of HFS biosynthesis such acid pH environment and high temperature which are harsh for wild-type enzymes. Therefore, there is a need to engineer a GRAS B. subtilis 168 for sustainable industrial production. Codon optimization and plasmid engineering have been highlighted.
\end{abstract}

Keywords-Glucose isomerase, isomerization, Bacillus Subtilis, high fructose syrup, biosynthesis.

\section{INTRODUCTION}

HFCS (high fructose corn syrup) is a refined and condensed functional sugar aqueous solution that is commonly used as a natural sweetener. It's among the most widely used sweeteners in soft drinks, ice cream, yogurt, tomato paste, chocolate milk, candy, condiments, jelly, and canned and processed foods [1-3]. Recently, HFCS has been regarded as a renewable resource for the manufacturing process of 5-hydroxymethylfurfural and levulinic acid, both of which can be used to synthesize other useful biopetrochemicals, such as green solvents, plastic materials, lubricants, and highly valued biofuels [48]. Enhanced iron and zinc absorption, insulin-independent metabolism, improved ethanol metabolism, low sugar and calorie content, and ideal sensory properties have all been demonstrated as health benefits of HFS consumption [2,9]. Furthermore, high sweetness, high solubility, low viscosity, enhanced taste, strong humectants, no side 
effects in acidic foods, and no crystal formation are all advantages of HFS over other sugars. [3,9,10].

Based on the fructose content, HFCS can be classified as HFCS-42, HFCS-55, or HFCS-90. However, since HFCS42 has a low fructose content and is easy to solidify and crystallize in low-temperature transport and storage due to its low fructose content, HFCS-55 with a higher fructose content has become the premium product $[1,2]$. Chemical catalysis and enzyme biocatalysis are two methods for producing HFCS. In an alkaline environment, chemical catalysis is the isomerization or acid hydrolysis of glucose to fructose [2].

For more than a century, it has been known that glucose can isomerize fructose by basic isomerization or acid hydrolysis, as shown in Figure 1. Therefore, it is a demanding process that leads to unacceptable sugar decomposition. In addition, the chemical synthesis of HFCS needs a higher calcination temperature, which is not friendly to the environment [11-13]. The problem of separation and recovery of homogeneous Lewis acid is common, and the synthesis of $\mathrm{Sn}-\beta$ zeolite is more complex. On the other hand, the isomerization of glucose to fructose can also be effectively achieved by ionic bases such as sodium hydroxide. In contrast, due to the serious degradation of fructose and glucose, the yield of fructose from glucose is low, and the separation and recovery of fructose is also a problem[4,12,14].

Since Yoshiyuki Takasaki discovered a thermostable glucose isomerase from yeast in the early 1970s, commercial HFC was mainly synthesized by microorganisms [15]. Glucose isomerase, also known as $\mathrm{D}$-xylose isomerase, is widely used in the production of HFCS. It not only catalyzes the conversion of D-glucose to D-fructose but also catalyzes the conversion of D-xylose to D-xylulose [16]. In recent years, with the increasing consumption of HFCS, the production level of GIase has been widely concerned. Many microbial strains, including Streptomyces sp. CH7 [17], Lactobacillus bifermentans [18], Bacillus coagulans [19], Streptomyces murinus, Hyperthermophilic Thermotoga [20], and Pseudomonas hydrophila [21], it is reported that glucose isomerase can be produced. Due to the increasing global demand for hydrofluorocarbons, the production level of D-glucose isomerase has been widely concerned, especially in the food and beverage industry. Because of the increased global demand for HFCS, the level of GIase production has gained considerable attention, especially in the food and beverages industry. Due to the low productivity and stability of enzymes produced by wild-type microorganisms under harsh conditions, a more efficient expression system is needed for the production of recombinant GIase with desired properties for large-scale production of HFCS.

To obtain an effective expression mechanism, Glase has been heterologously expressed in a variety of hosts[22,23], and a variety of fermentation techniques, including fedbatch and high-density fermentation, have been used. As a result, GIase expression has greatly improved; for example, Akdag et al.[24] announced that using a beet molasses-based feeding method, they achieved the highest recombinant GIase production, $35.3 \mathrm{U} / \mathrm{mL}$, in E. coli. Due to its well-known genetics' history, short generation time, and suitability for low-cost high-density fermentation, Escherichia coli is the most common heterologous host strain for the expression of recombinant proteins [25]. However, improvements in GIase production, especially concerning HFCS-55 manufacturing, are still valued for industrial applications.

Although one-step biosynthesis of HFS-55 has achieved certain results, most of its host strains previously investigated with higher potential yields are Escherichia coli BL21, but in the catalytic process, BL21 may bring harmful toxin that does not meet the requirements of food safety into the target products[26-28]. Therefore, it is very meaningful to realize the heterologous expression of glucose isomerase in food safety strains with clear research background and to safely synthesize HFS-55 high fructose syrup in one step.

However, food safety requires a thorough investigation of food-grade microorganisms. Bacillus subtilis 168, and some other non-pathogenic related Bacillus species, which are free of exotoxins and endotoxins, and have a recognized history of safe use in foods are very useful for fermentation and large-scale cultivation[29].

Thus, an efficient expression of recombinant GIase in a generally regarded safe strain is necessary for improved economic HFCS-55 manufacturing and can contribute more to food security.

In this review paper, HFS production approaches, Glucose Isomerase properties, plasmid vectors, hosts engineering methods strategies for efficient expression of recombinant proteins in Bacillus subtilis 168, are reviewed.

\section{THE INDUSTRIAL PRODUCTION PROCESS FOR HFS}

The chemical conversion of glucose to fructose has a history of more than a hundred years. Most methods are usually carried out at a high $\mathrm{pH}$, and temperatures. The possibility of chemical conversion of D-glucose into Dfructose has been studied and reported [30]. However, this reaction is non-specific and easily produces by-products 
and poor color-developing products fig.2. It is also difficult to obtain D-fructose concentrations above $40 \%$ by this method [25].

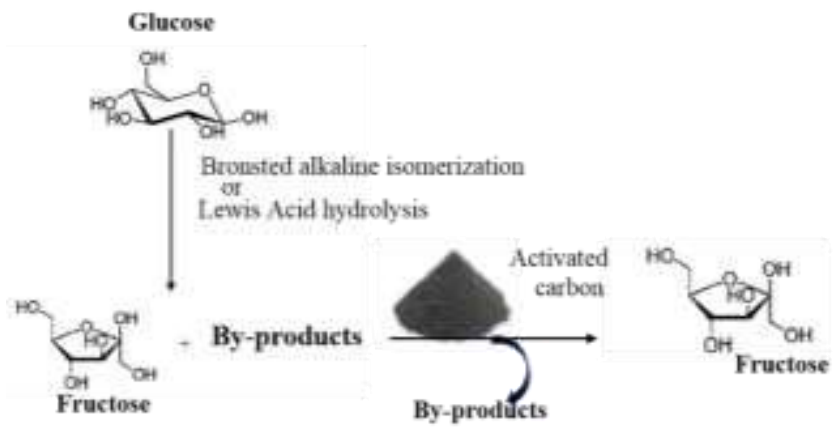

Fig. 1 Chemical process of high fructose syrup synthesis

In contrast, using glucose isomerase to convert glucose to fructose has several advantages over chemical methods, including (i) the specificity of the reaction, (ii) the mild $\mathrm{pH}$ and temperature conditions of the reaction, and (iii) a higher fructose ratio in the final product. Therefore, enzyme conversion is the first choice for HFS production[25].

High Fructose Corn Syrup has been produced from corn by recombinant glucose isomerase for more than 40 years. In modern industry, the production of HFC from starch includes three main processes fig. 3 Glucose isomerase is used to isomerize D-glucose into D-fructose with a mild basic environment under moderate $\mathrm{pH}$ conditions[11].Fig.2 represents in vitro isomerization of glucose into fructose.

The production of HFS is highly industrialized, and the processing aids used are best classified in the chemical laboratory. Both of these sweeteners are extracted from complex plant sources, which contain a large number of potential colors, odor, and flavor compounds that must be removed. Since foods and beverages manufacturers require high-purity sweeteners, there are no undesirable contaminants, and because process engineers can only obtain a few refining techniques, the isomerization process is illustrated below[11,31]:

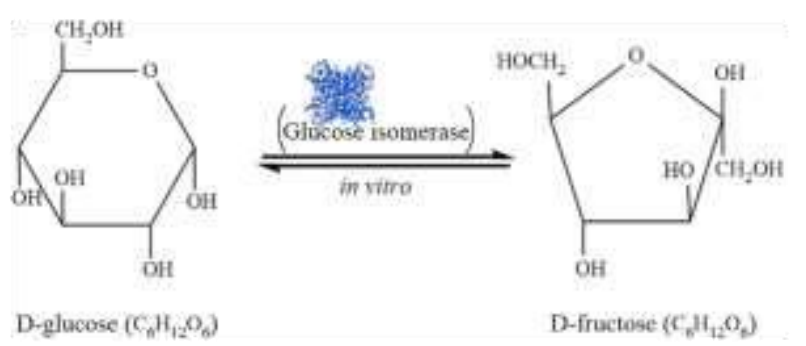

Fig. 2 Isomerization of D-glucose into D-fructose by recombinant $G I$

In general, the bioconversion process is referred to as fermentation which is a biochemical process in which carbohydrate molecules (such as glucose) are converted into energy, lactic acid, and other by-products according to the type of microorganisms involved in the fermentation processes[32]. There are two types i.e. Solid-state Fermentation which is related to solid-state fermentation, microbial growth and fermentation occur on the surface of a solid substrate and submerged Fermentation which in this fermentation process, the substrate for the growth of microorganisms is placed in a liquid solution in a big tank called a fermenter or bioreactor[33]. Submerged fermentation of fermented liquid can be subdivided into three categories:

- Batch fermentation: Put the substrates and raw materials required for fermentation and the required microbial growth into the bioreactor; when operating parameters such as $\mathrm{pH}$ value and thermal value are determined, culture is allowed. In the fermentation process, there is nothing except the addition of oxygen in the case of aerobic microorganisms. After each process is completed, the products are collected and the fermenter is cleaned; then, another batch of products can be prepared and the process can be restarted.

-Fed-batch fermentation: A small number of substrates and raw materials are added during the fermentation process. Both batch and fed-batch procedures are considered "closed" fermentation systems, different from "open" systems such as continuous fermentation [34]

- Continuous fermentation: In this process, the addition of substrates and raw materials is carried out continuously. Therefore, continuous fermentation is considered an open system: allowing the introduction of new raw materials, unlike a "closed" system [34].

Although batch isomerization is feasible in some modifications of stirred tank reactor systems[35].

Technically feasible, a continuous process using a fixed bed reactor has advantages.

Advantages of continuous isomerization process Compared with batch isomerization in a stirred tank.

1. The amount and cost of enzymes for converting glucose into fructose are low.

2. Reduce capital equipment and labor costs.

3. Better and easier process control.

4. Reduce refining costs and improve product quality. 


\section{MICROBIAL SOURCES OF GLUCOSE ISOMERASE}

The Most commercially available glucose isomerase genes are mined from some mesophilic microorganisms. The glucose isomerase is widely distributed in prokaryotes, many bacteria and actinomycetes have been found to produce Glucose Isomerase and most of them produce intracellular GI enzymes. Previous studies reported that only a few extracellular Glucose Isomerases are produced by Chainia spp, Staphylococcus aureus, and Streptomyces glaucescens. In addition to Streptomyces, some bacilli are also good producers of GI[36,37].

\section{CRYSTAL STRUCTURE OF GLUCOSE ISOMERASE}

Glucose or xylose isomerase catalyzes the reversible isomerization of D-glucose and D-xylose into D-fructose and D-xylulose, respectively, and is not only involved in sugar metabolism but also has other valuable industrial application, such as the production of high fructose syrup and biofuels[38,39]. Various structural crystals of glucose isomerase demonstrate the binding configuration of the substrate and its molecular mechanism. However, the metal-binding mechanism required for the isomerization reaction has not been described[39]. Based on primary amino acid sequence homology, Glucose isomerases are divided into two categories, namely class I and class II. The main difference between them is that the second type of enzyme contains an extra insertion of approximately 4050 amino acid residues in the $\mathrm{N}$-terminal domain and although the homology of the primary sequences of the two classes is low (25-30\%), their three-dimensional structures are similar fig. $3[16,38]$. The crystal structures of some GIs derived from microorganisms, such as Streptomyces rubiginosus, Streptomyces olivochromogenes, and Actinoplanes missouriensis, have been identified and show a high degree of structural homology[40]. The enzyme catalytic capsule at the $\mathrm{N}$ terminus of the GI monomer and two metal-binding sites are folded into an eight-stranded $(\beta / \alpha)$ catalytic pocket, and the C-terminus is folded into a large ring, which can overlap with the N-terminus of another subunit to form a tightly bound dimer body which are associated with noncovalent bonds[38,41]. Currently, commercial GIs as HFS producers mainly come from Bacillus coagulans, Streptomyces murinus, and Streptomyces rubiginosis[21]. However, the disadvantage of using these enzymes is that when the isomerization temperature rises above $60^{\circ} \mathrm{C}$, their catalytic performance is poor, and subsequent chromatographic separation is expensive to obtain the desired D-fructose concentration of HFS. Thus, looking for heat-resistant GIs that produce HFS at high temperatures and increase the yield of D-fructose is considered to be an effective way to reduce the cost of improvement[42,43].Glucose Isomerases are homotetramer with the monomer molecular weights ranging in between $43-53 \mathrm{kDa}$.The tetramer appears to be a living unit, but the monomer is inactive. The Monomers are combined with non-covalent bonds and lack interchain disulfides. Each monomer has two metal binding sites, which are combined with $\mathrm{Mg}^{2+}, \mathrm{Co}^{2+}$ or $\mathrm{Mn}^{2+}$, and are necessary for catalytic activity and thermal stability. The monomer has $8 \alpha$-helices and $8 \beta$ sheets an alpha-beta barrel motif[36].

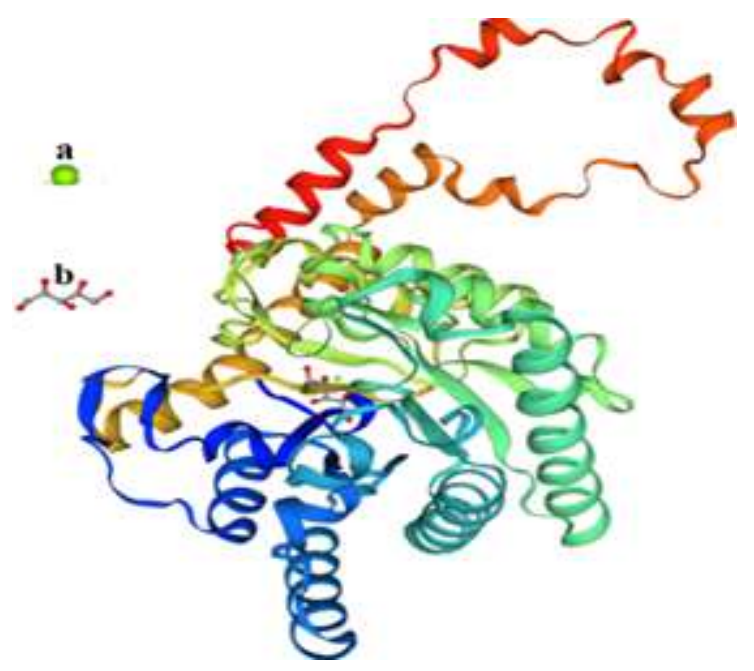

Fig. 3 3D carton Homo-tetramer structure model of GI: an overview of GI-ligands interaction in $3 D$ dimension, green ball (a) represents Magnesium and (b) represents ligand.

(https://swissmodel.expasy.org/interactive/8S3uUT/models )

\section{PHYSICAL-CHEMICAL PROPERTIES OF GLUCOSE ISOMERASE}

Various substrates. pentose, hexose, both sugar alcohol, and Phosphate can be bio-converted by enzymes. This protein has different affinities and can utilize D-ribose, Lrhamnose, L-arabinose, 2-deoxyglucose, and D-allose like the most very common substrates D-xylose and D-glucose [25]. The glucose isomerase is significantly stabilized and activated divalent cations, especially $\mathrm{Mg}^{2+}, \mathrm{Co}^{2+}$ and $\mathrm{Mn}^{2+}$ ions. It is generally believed that $\mathrm{Mg}^{2+}$ is the main activator of Glucose Isomerase. The divalent $\mathrm{Co}^{2+}$ plays a vital role in the activity of the enzyme, but it is best to maintain the stability of the GI enzymes by maintaining the molecular structures of the proteins, especially the quaternary structures [44,45]. Other metal ions such as $\mathrm{Hg}^{2+}, \mathrm{Ag}^{+}, \mathrm{Zn}^{2+}, \mathrm{Cu}^{2+}, \mathrm{Ni}^{2+}$ can inhibit the catalytic activity of GI enzymes, especially $\mathrm{Ca}^{2+}$ in the initial stage of industrial biosynthesis. In the early stage of producing 
HFCs, $\mathrm{Ca}^{2+}$ can be used as a cofactor for the glucan 1,4-aglucosidases the next step to produce glucose syrup as a substrate for glucose isomerase. Excessive residual $\mathrm{Ca}^{2+}$ inevitably inhibits the glucose isomerase enzyme activity and which reduces the conversion rate, yield, and productivity of High Fructose Syrup. Therefore, the process to remove calcium ions before the isomerization of glucose syrup is an essential process in industrial production. Other known GI activity inhibitors are substrate analogs such as arabitol, xylitol, mannitol, and sorbitol[46]. The optimum temperature range for GI for most commercial applications is 55 to $65^{\circ} \mathrm{C}$ which increases in the presence of cobalt ions. The optimal $\mathrm{pH}$ ranges for GI activity generally range in between $\mathrm{pH} 7.0$ 9.0. According to recent reported studies, it has been found that many thermostable glucose isomerases have higher optimal reaction temperatures[47].

\section{FUNDAMENTAL ELEMENTS FOR HIGH LEVEL EXPRESSION OF RECOMBINANT PROTEINS}

The expression of recombinant protein is realized by several steps, and the overall steps are shown in Figure 5. The two main components of recombinant protein expression are expression vector and expression host / compatible host.

\subsection{Gene design}

Direct synthesis of genes is rapidly becoming the most effective way to produce genes Construction and application of functional genes, such as codon optimization[48].

\subsubsection{Codon Optimization}

To select a gene for optimal expression needs to select from a large number of sequences. For example, in theory, a protein with an average size of $30 \mathrm{kDa}$ could be encoded by $10^{100}$ possible DNA sequences. Historically, there have been two approaches to codon optimization. The first, named "one amino acid, one codon", use the most abundant codon of the host to encode all occurrences of a given amino acid in the optimized sequence. The second method, called "codon randomization", uses translation tables based on the frequency distribution of codons across the genome or in a subset of highly expressed genes[49]. Codon optimization consists of the replacement of codons to meet the host codon bias, and this aims to increase gene expression[50]. Recombinant protein expression using bacterial and other host organisms is a fundamental technology for protein production. A key step in recombinant protein expression is codon optimization where a coding sequence for a protein of interest is designed by synonymous substitution directing to increase its expression level[51]. The substitution of rare codons in the introduced gene may increase the yield dramatically. Besides, the replacement of rare codons might decrease the chance of misincorporation and protect the protein from premature turnover[52]. Current approaches to codon optimization are based on sequence features considered to influence protein expression levels. As an example, a conventional approach is to substitute rare codons with frequent codons according to the genomic codon usage in a host organism. The basis of this approach is that endogenous genes whose coding sequences consist of frequent codons have high protein expression levels, and therefore, recombinant protein expression is also considered to be improved by increasing the codon frequency. Besides, aiming to introduce synonymous substitution computationally predicted to destabilize mRNA secondary structures since the stable messenger RNA secondary structures may inhibit translation, this approach is taken into consideration to improve recombinant protein expression by enhancing translational efficiency[51,53,54].

The genetic information carried by mRNA and then translated into proteins is encoded into nucleotide triplets called codons. Four alternate nucleotidic bases (A, U, C, G) compose mRNA so that $4^{3}=64$ possibilities of codons which code for only 20 naturally occurring amino acids. The genetic code is therefore redundant: while a few amino acids correspond to a single codon, most amino acids can be encoded by different codons. Different codons coding for the same amino acid are known as synonymous codons, and in a wide variety of organisms synonymous codons are used with different frequencies "a phenomenon is known as codon bias" [55,56]. Various factors such as expression level, GC content, recombination rates, RNA stability, codon position, gene length, environmental stress, and population size, can influence codon usage bias within and among species. These observations stress the potential of the new index to both measures and explain codon usage bias, particularly as related to speed and accuracy of gene translation and protein synthesis and this approach has been widely used for designing synthetic genes to improve their expression in the heterologous host organisms[56,57].

\subsubsection{Expression Vector}

The design of the vector expression vector enables the cloned gene to be transcribed and/or translated. It contains all the components that express foreign genes. Plasmid vector was used for cloning and expression of the foreign gene in the prokaryotic system[58]. Therefore, the expression vector used has elements specific to those used 
in a particular system. The basic components of the expression vector are shown in Fig. 4.

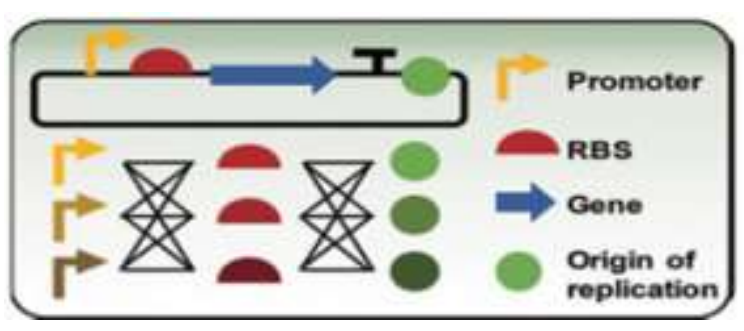

Fig. 4 Plasmid-based engineering

\subsubsection{Promoter}

The promoter is a key component of the expression system because it controls the transcription initiation of related genes. An ideal promoter should exhibit several desirable characteristics: (i) it should be strong enough to allow the product to accumulate up to $50 \%$ of the total cell protein; (ii) it should be strictly regulated to prevent product toxicity. Constitutive promoters do not allow efficient production of toxic proteins / some natural proteins that are harmful to cells when overexpressed. One example is a membrane protein, which can cause cell death when overproduced in the host, possibly by jamming the inner membrane[58,59].

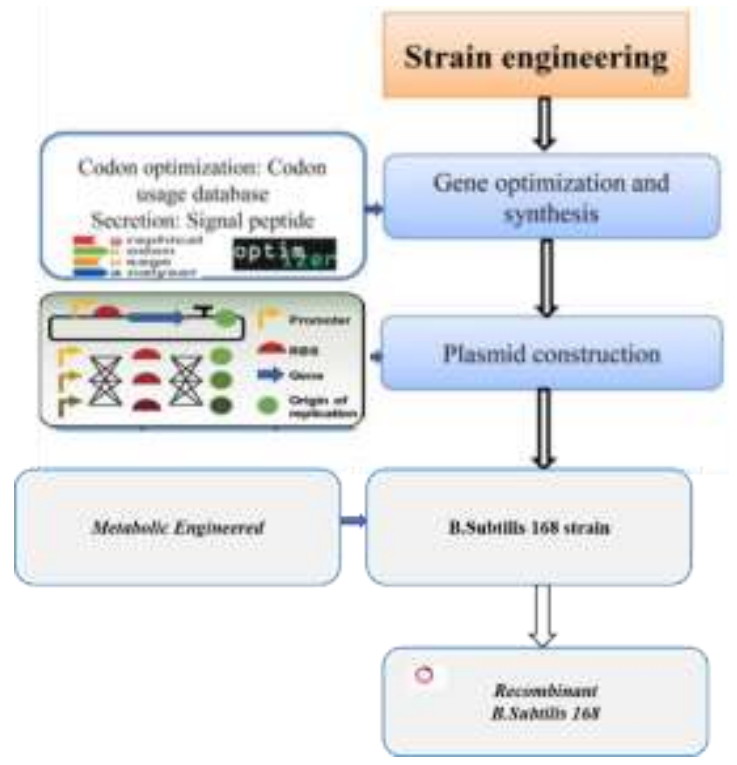

Fig. 5 Engineered recombinant B. Subtilis 168 for highlevel protein expression

\section{INDUSTRIAL APPLICATIONS OF HIGH FRUCTOSE SYRUP}

Currently, HFCS-55 is highly more suitable for industrial applications fig.7 [60]. ]. Because of its better function and Technical advantages compared with sucrose, such as better solubility, higher sweetness, stability, and lower prices[61], use of HFCS in beverages, baking, canning, and confectionery the industry as an alternative sweetener and food additive is increasingly[11,62]. 5hydroxymethylfurfural (HMF) can be produced from a variety of raw materials, including hexose and polysaccharides [63]. Fructose is usually an effective and selective starting material for HMF production, which can achieve faster conversion at a higher yield than glucose [61]. However, due to its cost-effectiveness, glucose is often used in the production of HMF in industrial production Costs [63]. HMF is produced by dehydration of fructose and induced by acid or metal catalyst[61]. Besides, HFS can be used as raw material for valuable biobased fine chemicals such as biofuels, green solvents, and lubricants, plastics[64].

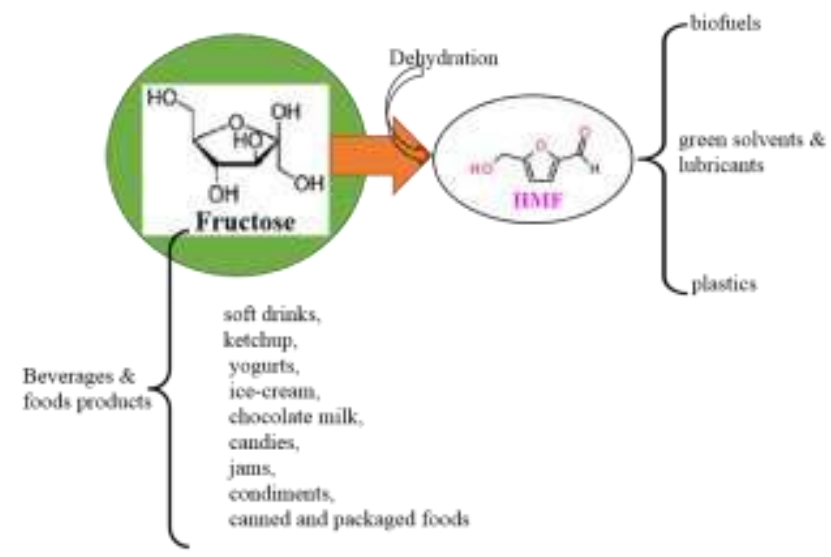

Fig. 6 Industrial applications of Fructose

\section{CONCLUSION}

Due chemical hydrolysis of D-glucose into D-fructose which has several challenges and disadvantages, in recent decades' researchers have attached their attention to Enzymatic isomerization which revealed excellent economical potentials over the classical method.

Benefits of codon optimization in Industrial Biotechnology in the past ten years, nothing has been strongly proved and this technology is rapidly being adopted to remain competitive in the current market. This example shows that there is only one or several synthetic genes a host needs to be introduced to generate new products or directly reduce the existing production costs. The cost of gene synthesis is decreasing in the past decade; and the technology of assembling large pieces and multiple worlds changing at the same time type genome becoming available. Thus, we can envision a future where custommade microorganisms can be designed for a particular application. One of the areas in which these new technologies can play a role Dramatic contribution toward the production of chemicals by microbial cell factories. 
Start moving towards that goal It is adopted in the industry.

Furthermore, engineering promoters can accelerate the level of recombinant protein expression which contributes more to large-scale protein production. Thus, strong promoters are highly recommended for microbial strain engineering.

\section{REFERENCES}

[1] L. Jin, Q. Xu, Z. Liu, Immobilization of Recombinant Glucose Isomerase for Efficient Production of High Fructose Corn Syrup, (2017). https://doi.org/10.1007/s12010-017-2445-0.

[2] R.S. Singh, K. Chauhan, A. Pandey, C. Larroche, Biocatalytic strategies for the production of high fructose syrup from inulin, Bioresour. Technol. (2018). https://doi.org/10.1016/j.biortech.2018.03.127.

[3] K. Sollid, M.S. Edge, A. Bouchoux, A Closer Look at Sugars, 20036

(2012). https://doi.org/10.1097/NT.0b013e3182435de8.

[4] Q. Yang, S. Zhou, T. Runge, Magnetically separable base catalysts for isomerization of glucose to fructose, J. Catal. $330 \quad$ (2015) 474-484. https://doi.org/10.1016/j.jcat.2015.08.008.

[5] R. Van Putten, J.C. Van Der Waal, E. De Jong, C.B. Rasrendra, H.J. Heeres, J.G. De Vries, Hydroxymethylfurfural , A Versatile Platform Chemical Made from Renewable Resources, (2013).

[6] M. Woodley, A. Riisager, T. Sta, Catalysis Science \& Technology Enzymatic isomerization of glucose and xylose in ionic liquids $\mathrm{w}$, (2012) 291-295. https://doi.org/10.1039/c1cy00155h.

[7] C. Liu, J.M. Carraher, J.L. Swedberg, C.R. Herndon, C.N. Fleitman, Selective Base-Catalyzed Isomerization of Glucose to Fructose, (2014).

[8] Q. Yang, M. Sherbahn, T. Runge, Basic Amino Acids as Green Catalysts for Isomerization of Glucose to Fructose in Water,

(2016). https://doi.org/10.1021/acssuschemeng.6b00587.

[9] S. Neifar, F. V Cervantes, A. Bouanane-darenfed, H. Benhlima, A.O. Ballesteros, F.J. Plou, S. Bejar, Immobilization of the glucose isomerase from Caldicoprobacter algeriensis on Sepabeads EC-HA and its efficient application in continuous High Fructose Syrup production using packed bed reactor, Food Chem. (2019) 125710. https://doi.org/10.1016/j.foodchem.2019.125710.

[10] D. Jia, L. Zhou, Y. Zheng, Properties of a novel thermostable glucose isomerase mined from Thermus oshimai and its application to preparation of high fructose corn syrup, Elsevier Inc., n.d. https://doi.org/10.1016/j.enzmictec.2017.01.001.

[11] J.S. White, Sucrose , HFCS , and Fructose: History , Manufacture, Composition, Applications , and Production,
(2014). https://doi.org/10.1007/978-1-4899-8077-9.

[12] X. Li, X. Zhang, H. Li, J. Long, Glucose Isomerizes to Fructose Catalyzed by the Eco- Friendly and Biodegradable Ionic Liquids, (2019) 13731-13735. https://doi.org/10.1002/slct.201904192.

[13] C. Li, Y. Wang, Y. Zhang, M. Wang, X. Sun, H. Cui, Isomerization Kinetics of Glucose to Fructose in Aqueous Solution with Magnesium-Aluminum Hydrotalcites, (2020) 270-279. https://doi.org/10.1002/slct.201903959.

[14] I. Delidovich, Recent progress in base-catalyzed isomerization of D-glucose into D-fructose, Curr. Opin. Green Sustain. Chem. $27 \quad$ (2021) 100414. https://doi.org/10.1016/j.cogsc.2020.100414.

[15] Takasaki et al., Enzyma method for converting glucose in glucose syrups to fructose, 1965.

[16] D.-X. Jia, L. Zhou, Y.-G. Zheng, Properties of a novel thermostable glucose isomerase mined from Thermus oshimai and its application to preparation of high fructose corn syrup, Enzyme Microb. Technol. 99 (2017) 1-8. https://doi.org/https://doi.org/10.1016/j.enzmictec.2017.01. 001 .

[17] K. Chanitnun, P. Pinphanichakarn, Glucose(xylose) isomerase production by Streptomyces sp. $\mathrm{CH} 7$ grown on agricultural residues, Braz. J. Microbiol. 43 (2012) 10841093. https://doi.org/10.1590/S1517838220120003000035 .

[18] S. Givry, F. Duchiron, Optimization of culture medium and growth conditions for production of L-arabinose isomerase and D-xylose isomerase by Lactobacillus bifermentans, Microbiology. $\quad 77 \quad$ (2008) 281-287. https://doi.org/10.1134/S0026261708030053.

[19] Helle Outtrup, Production of glucose isomerase by bacillus coagulans, 1973.

[20] R.K. Bandlish, J.M. Hess, K.L. Epting, C. Vieille, R.M. Kelly, Glucose-to-fructose conversion at high temperatures with xylose (glucose) isomerases from Streptomyces murinus and two hyperthermophilic Thermotoga species, Biotechnol. Bioeng. 80 (2002) 185-194. https://doi.org/10.1002/bit.10362.

[21] R. Di Cosimo, J. Mc Auliffe, A.J. Poulose, G. Bohlmann, Industrial use of immobilized enzymes, Chem. Soc. Rev. 42 (2013) 6437-6474. https://doi.org/10.1039/c3cs35506c.

[22] S. Rehman, H.N. Bhatti, M. Bilal, M. Asgher, Cross-linked enzyme aggregates (CLEAs) of Pencilluim notatum lipase enzyme with improved activity, stability and reusability characteristics, Int. J. Biol. Macromol. 91 (2016) 11611169. https://doi.org/10.1016/j.ijbiomac.2016.06.081.

[23] N. Zhang, X.G. Meng, Y.Y. Wu, H.J. Song, H. Huang, F. Wang, J. Lv, Highly Selective Isomerization of Glucose into Fructose Catalyzed by a Mimic Glucose Isomerase, ChemCatChem. $11 \quad$ (2019) 2355-2361. https://doi.org/10.1002/cctc.201900143.

[24] Y. Ge, H. Zhou, W. Kong, Y. Tong, S. Wang, W. Li, Immobilization of glucose isomerase and its application in 
continuous production of high fructose syrup, Appl. Biochem. Biotechnol. - Part A Enzym. Eng. Biotechnol. 69 (1998) 203-215. https://doi.org/10.1007/BF02788814.

[25] S.H. Bhosale, M.B. Rao, V. V Deshpande, Molecular and Industrial Aspects of Glucose Isomerase, 60 (1996) 280 300.

[26] C.L. Holmes, M.T. Anderson, H.L.T. Mobley, M.A. Bachman, Pathogenesis of Gram-Negative Bacteremia, Clin. Microbiol. Rev. 34 (2021) e00234-20. https://doi.org/10.1128/CMR.00234-20.

[27] M.Q. Carter, A. Pham, S. Huynh, C.T. Parker, A. Miller, X. He, B. Hu, P.S.G. Chain, DNA adenine methylase, not the PstI restriction-modification system, regulates virulence gene expression in Shiga toxin-producing Escherichia coli, $\begin{array}{lllll}\text { Food } & \text { Microbiol. } & 96 & \text { (2021) } & 103722 .\end{array}$ https://doi.org/10.1016/j.fm.2020.103722.

[28] W. Elmonir, S. Shalaan, A. Tahoun, S.F. Mahmoud, E.M.A. Remela, R. Eissa, H. El-Sharkawy, M. Shukry, R.N. Zahran, Prevalence, antimicrobial resistance, and genotyping of Shiga toxin-producing Escherichia coli in foods of cattle origin, diarrheic cattle, and diarrheic humans in Egypt, Gut Pathog. 13 (2021) 1-11. https://doi.org/10.1186/s13099-021-00402-y.

[29] H. Dong, D. Zhang, Current development in genetic engineering strategies of Bacillus species, Microb. Cell Fact. 13 (2014) 1-11. https://doi.org/10.1186/1475-285913-63.

[30] W. Hatt, A.E. Marantz, United States Patent ( 19 ), (1975).

[31] C.C. Akoh, S.W. Chang, G.C. Lee, J.F. Shaw, Biocatalysis for the production of industrial products and functional foods from rice and other agricultural produce, J. Agric. Food Chem. $56 \quad$ (2008) 10445-10451. https://doi.org/10.1021/jf801928e.

[32] R.P. John, K.M. Nampoothiri, Fermentative production of lactic acid from biomass: an overview on process developments and future perspectives, (2007) 524-534. https://doi.org/10.1007/s00253-006-0779-6.

[33] S.M. Ameen, SPRINGER BRIEFS IN MOLECULAR SCIENCE Lactic Acid in the Food Industry, n.d.

[34] B.A.D. Portno, -oho 100, 74 (1968).

[35] B.B. Schnyder, Continuous 1somerization of Glucose to Fructose on a Commercial Basis *, (1969).

[36] T. Submitted, P. Fulfillment, H.K. June, H. Kong, Genetic Engineering Improvement of Glucose Isomerase, (2004).

[37] S. Neifar, H. Ben Hlima, S. Mhiri, M. Mezghani, K. Bouacem, A.H. Ibrahim, B. Jaouadi, A. BouananeDarenfed, S. Bejar, A novel thermostable and efficient Class II glucose isomerase from the thermophilic Caldicoprobacter algeriensis: Biochemical characterization, molecular investigation, and application in High Fructose Syrup production, Int. J. Biol. Macromol. 129 (2019) 3140.

https://doi.org/https://doi.org/10.1016/j.ijbiomac.2019.01.1 50 .
[38] H. Deng, S. Chen, D. Wu, J. Chen, J. Wu, Heterologous expression and biochemical characterization of glucose isomerase from Thermobifida fusca, Bioprocess Biosyst. Eng. 37 (2014) 1211-1219. https://doi.org/10.1007/s00449013-1093-1.

[39] K.H. Nam, Crystal structure of the metal-free state of glucose isomerase reveals its minimal open configuration for metal binding, Biochem. Biophys. Res. Commun. 547 (2021) $69-74$. https://doi.org/https://doi.org/10.1016/j.bbrc.2021.02.026.

[40] J.W. Cho, B.G. Han, S.Y. Park, S.J. Kim, M.D. Kim, B. Il Lee, Overexpression, crystallization and preliminary X-ray crystallographic analysis of a putative xylose isomerase from Bacteroides thetaiotaomicron, Acta Crystallogr. Sect. F Struct. Biol. Cryst. Commun. 69 (2013) 1127-1130. https://doi.org/10.1107/S1744309113023877.

[41] H. Ben Hlima, S. Bejar, J. Riguet, R. Haser, N. Aghajari, Identification of critical residues for the activity and thermostability of Streptomyces sp. SK glucose isomerase, Appl. Microbiol. Biotechnol. 97 (2013) 9715-9726. https://doi.org/10.1007/s00253-013-4784-2.

[42] H. Karaoglu, D. Yanmis, F.A. Sal, A. Celik, S. Canakci, A.O. Belduz, Biochemical characterization of a novel glucose isomerase from Anoxybacillus gonensis G2T that displays a high level of activity and thermal stability, J. Mol. Catal. B Enzym. 97 (2013) 215-224. https://doi.org/10.1016/j.molcatb.2013.08.019.

[43] S.H. Brown, C. Sjøholm, R.M. Kelly, Purification and characterization of a highly thermostable glucose isomerase produced by the extremely thermophilic eubacterium, Thermotoga maritima, Biotechnol. Bioeng. 41 (1993) 878886. https://doi.org/10.1002/bit.260410907.

[44] M. Callens, P. Tomme, H. Kersters-Hilderson, R. Cornelis, W. Vangrysperre, C.K. De Bruyne, Metal ion binding to dxylose isomerase from Streptomyces violaceoruber, Biochem. J. $250 \quad$ (1988) 285-290. https://doi.org/10.1042/bj2500285.

[45] C. December, 1989 Academic, Biochem. Biophys. Res. Commun. 165 (1989) 1155-1161.

[46] R.K. Ball, R.R. Friis, C. a Schoenenberger, W. Doppler, and Expression, Genetics. 91 (1994) 1554-1563. http://www.ncbi.nlm.nih.gov/entrez/query.fcgi?cmd=Retrie ve $\& d b=$ PubMed\&dopt=Citation\&list_uids=7991537.

[47] M. Suekane, M. Tamura, C. Tomimura, Physico-chemical and enzymatic properties of purified glucoseisomerases from streptomyces olivochromogenes andbacillus stearothermophilus, Agric. Biol. Chem. 42 (1978) 909-917. https://doi.org/10.1080/00021369.1978.10863087.

[48] A. Villalobos, J.E. Ness, C. Gustafsson, J. Minshull, S. Govindarajan, Gene Designer: A synthetic biology tool for constructuring artificial DNA segments, BMC Bioinformatics. 7 (2006) 1-8. https://doi.org/10.1186/14712105-7-285.

[49] C. Elena, P. Ravasi, M.E. Castelli, S. Peirú, H.G. Menzella, Expression of codon optimized genes in microbial systems: 
Current industrial applications and perspectives, Front. Microbiol. $\quad 5 \quad$ (2014) $1-8$. https://doi.org/10.3389/fmicb.2014.00021.

[50] H. (Professor) Zhao, A.-P. (An-P. Zeng, Synthetic Biology - Metabolic Engineering, 2018. https://books.google.co.cr/books?id=urc7DwAAQBAJ\&pg $=$ PR5\&dq=metabolic+engineering $\& \mathrm{hl}=\mathrm{es} \& \mathrm{sa}=\mathrm{X} \& \mathrm{ved}=0 \mathrm{ah}$ UKEwj-

iIvlyancAhVDj1kKHQ21C6EQ6AEIJjAA\#v=onepage\&q\& $\mathrm{f}=$ false\%0Ahttp://link.springer.com/10.1007/978-3-31955318-4.

[51] Y. Saito, W. Kitagawa, T. Kumagai, N. Tajima, Developing a codon optimization method for improved expression of recombinant proteins in actinobacteria, Sci. Rep. (2019) 1-10. https://doi.org/10.1038/s41598-01944500-z.

[52] A. Fuglsang, Codon optimizer: A freeware tool for codon optimization, Protein Expr. Purif. 31 (2003) 247-249. https://doi.org/10.1016/S1046-5928(03)00213-4.

[53] P. Rehbein, J. Berz, P. Kreisel, H. Schwalbe, “ CodonWizard " - An intuitive software tool with graphical user interface for customizable codon optimization in protein expression efforts, Protein Expr. Purif. 160 (2019) 84-93. https://doi.org/10.1016/j.pep.2019.03.018.

[54] C.G. Kurland, Codon bias and gene expression, 285 (1991) 165-169.

[55] V.P. Mauro, S.A. Chappell, A critical analysis of codon optimization in human therapeutics, Trends Mol. Med. (2014)

$1-10$. https://doi.org/10.1016/j.molmed.2014.09.003.

[56] M. Dilucca, G. Cimini, A. Semmoloni, A. Deiana, A. Giansanti, Codon Bias Patterns of E . coli's Interacting Proteins, (2015) 1-18. https://doi.org/10.1371/journal.pone.0142127.

[57] J.X. Chin, B.K. Chung, D. Lee, Sequence analysis Codon Optimization On-Line ( COOL ): a web-based multiobjective optimization platform for synthetic gene design, (2014) 1-2.

[58] J. Kaur, A. Kumar, J. Kaur, Strategies for optimization of heterologous protein expression in E. coli: Roadblocks and reinforcements, Int. J. Biol. Macromol. 106 (2018) 803822. https://doi.org/10.1016/j.ijbiomac.2017.08.080.

[59] P. Stargardt, L. Feuchtenhofer, M. Cserjan-Puschmann, G. Striedner, J. Mairhofer, Bacteriophage Inspired GrowthDecoupled Recombinant Protein Production in Escherichia coli, ACS Synth. Biol. 9 (2020) 1336-1348. https://doi.org/10.1021/acssynbio.0c00028.

[60] N. Fatourehchi, M. Sohrabi, B. Dabir, S.J. Royaee, Application of a novel type impinging streams reactor in glucose conversion to fructose using glucose isomerase enzyme, J. Chem. Technol. Biotechnol. 89 (2014) 19181923. https://doi.org/10.1002/jctb.4276.

[61] T. Barclay, M. Ginic-markovic, P.D. Cooper, N. Petrovsky, R. Article, The chemistry and sources of fructose and their effect on its utility and health implications ., 3 (2012) 6782.

[62] J. Huang, Z. Chen, W. Zhang, T. Zhang, W. Mu, D-Lyxose Isomerase and Its Application for Functional Sugar Production, Appl. Microbiol. Biotechnol. 102 (2018) 20512062. https://doi.org/10.1007/s00253-018-8746-6.

[63] J. Lewkowski, Synthesis, chemistry and applications of 5hydroxymethyl-furfural and its derivatives, Arkivoc. 2001 (2001)

$17-54$. https://doi.org/10.3998/ark.5550190.0002.102.

[64] Y. Wang, Y. Huang, L. Liu, L. He, T. Li, C. Len, W. Yang, Molecular Oxygen-Promoted Synthesis of Methyl Levulinate from 5-Hydroxymethylfurfural, ACS Sustain. Chem. $\quad$ Eng. 8 (2020) 14576-14583. https://doi.org/10.1021/acssuschemeng.0c05527. 